\title{
Design of the long-term observational cohort study with recombinant human growth hormone in Korean children: LG Growth Study
}

Sochung Chung, MD, PhD', JaeHo Yoo, MD, PhD², Jin Ho Choi, $M D, P^{3}$, Young-Jun Rhie, $\mathrm{MD}, \mathrm{PhD}^{4}$, Hyun-Wook Chae, $M D^{5}$, Jae Hyun Kim, $M D^{6}$, II Tae Hwang, MD, $\mathrm{PhD}^{7}$, Choong Ho Shin, MD, $\mathrm{PhD}^{8}$, Eun Young Kim, MS $^{9}$, Kee-Hyoung Lee, MD, $\mathrm{PhD}^{10}$

'Department of Pediatrics, Konkuk University Medical Center, Konkuk University School of Medicine, Seoul, ${ }^{2}$ Department of Pediatrics, Dong-A University College of Medicine, Busan, ${ }^{3}$ Department of Pediatrics, Asan Medical Center, Seoul, ${ }^{4}$ Department of Pediatrics, Korea University Ansan Hospital, Korea University College of Medicine, Ansan, ${ }^{5}$ Department of Pediatrics, Gangnam Severance Hospital, Seoul, ${ }^{6}$ Department of Pediatrics, Seoul National University Bundang Hospital, Seongnam, ${ }^{7}$ Department of Pediatrics, Kangdong Sacred Heart Hospital, Hallym University College of Medicine, Seoul, ${ }^{8}$ Department of Pediatrics, Seoul National University College of Medicine, Seoul, 'LG Chem, Ltd., Seoul, ${ }^{10}$ Department of Pediatrics, Korea University Anam Hospital, Seoul, Korea

Received: 17 November, 2017

Revised: 24 December, 2017

Accepted: 29 December, 2017

Address for correspondence: Kee-Hyoung Lee, MD

Department of Pediatrics, Korea University Anam Hospital, 73 Inchon-ro, Seongbuk-gu, Seoul 02841, Korea

Tel: +82-2-920-6604

Fax: +82-2-922-7476

E-mail: khlee218@kumc.or.kr

https://orcid.org/0000-0002-43199019
Purpose: Regarding recombinant human growth hormone (rhGH) use in the pediatric population, no long-term follow-up data are available for Korean patients. To fill in the gap of knowledge, a registry study (LG Growth Study) was initiated to assess the safety and effectiveness of four types of rhGH products in real-life settings.

Methods: A total of 4,000 children will be registered and prospectively followed up at 6-month intervals until 2 years after epiphyseal closure to collect data on treatment and adverse events, with primary interest in malignancies and growth outcomes.

Results: As of 22 March 2017, approximately 50\% $(2,024)$ of the target number of patients have been included in the analysis set: growth hormone deficiency, 1,297 (64.1\%); idiopathic short stature, 315 (15.6\%); small for gestational age, $206(10.2 \%)$; Turner syndrome, 197 (9.7\%); and chronic renal failure, $9(0.4 \%)$. At baseline, median age (years) was 8 (interquartile range [IQR], 5-11); 52\% $(1,048)$ were boys; and the majority were at Tanner stage I ( $83 \%$ based on breast/external genitalia, $97 \%$ on pubic hair). Median height standard deviation score was -2.26 (IQR, -2.69 to -2.0$)$, and median bone age delay (years) was -1.46 (IQR, -2.26 to -0.78 ).

Conclusion: This registry study will provide the opportunity to assess the risk of malignancies as well as the general safety data in Korean pediatric patients receiving $\mathrm{rhGH}$. In addition, the long-term effectiveness of rhGH and comparative data between different disease entities will provide practical insight on the standard rhGH treatment.

Keywords: Growth hormone deficiency, Turner syndrome, Chronic renal failure, Small for gestational age, Idiopathic short stature

\section{Introduction}

Growth hormone (GH), secreted from the anterior lobe of the pituitary gland, plays the essential role in somatic growth and regulates the metabolism of lipid and carbohydrate as well by mediation of insulin-like growth factors (IGFs). Hence, various conditions causing GH deficiency (GHD), either of congenital or acquired forms, are manifested mainly by stunted growth and also by altered body composition and dyslipidemia. ${ }^{1)}$ For treatment of GHD injection of external source of GH has been proved to be effective. Initially, GH derived from pituitary glands of human cadavers were used; however, its risk of transmitting CreutzfeldtJakob disease prevented its use. ${ }^{2)}$ Since 1985, cadaveric GH was replaced by recombinant human GH (rhGH), which has been extensively used to treat growth disturbances linked to GHD, and its indication in pediatric patients now is expanded to other conditions, such as Turner syndrome (TS), Prader-Willi syndrome, children born small for gestational age (SGA) 
without catch-up growth, chronic renal failure (CRF), idiopathic short-stature (ISS), Noonan syndrome, and SHOX-gene haploinsufficiency depending on the countries and products. ${ }^{3-5)}$

Based on more than 30 years of experience in the use of rhGH and accumulated clinical trial data, rhGH is generally considered to be safe; however, a number of safety issues with regard to mortality, cancer risk, cardiovascular diseases, and metabolic syndrome in the rhGH treated population still require more surveillance. ${ }^{6}$ Regarding efficacy data, most of the results obtained from regulatory trials are based on the limited period of follow-up with a duration range from 3 months up to 1 or 2 years at most, which mostly do not address the efficacy of rhGH on the final height. To answer these clinical questions, several long-term follow-up studies of various research methodologies have been initiated. ${ }^{7-9)}$ Even so, no relevant longterm data have been available for Korean pediatric population who have been treated under local clinical settings.

Thus, we planned to collect the real-life data of the following four products used in Korea: (1) Eutropin inj. (LG Chem, Osong, Korea) is an immediate-release formulation for daily subcutaneous injection (hereafter referred to as daily rhGH) and supplied as lyophilized powder. Eutropin inj. has been widely used in Korea since its initial approval in 1992; (2) Eutropin AQ inj. (LG Chem, Iksan, Korea) is also a daily rhGH supplied as a liquid formulation; (3) Eutropin Pen inj. (LG Chem, Osong) is a disposable pen type of daily rhGH.; and (4) Eutropin Plus inj. (LG Chem, Iksan), hereafter referred to as weekly rhGH) is a sustainedrelease formulation using sodium hyaluronate microparticles and is given once weekly via subcutaneous injection after dispersed in an oil base of medium-chain triglycerides. ${ }^{10)}$ All products are produced in Saccharomyces cerevisiae by recom- binant DNA technology. The efficacy and safety of these products in pediatric population have been shown for GHD, ${ }^{11-13}$ SGA, ${ }^{14)}$ TS $^{15)}$ and ISS ${ }^{16)}$ in several clinical trials, most of which address the short-term effect and limited safety.

To complement the existing data and fill in the gap of knowledge, we designed this observational cohort study based on a registry system to investigate the long-term safety and effectiveness of rhGH under approved pediatric indications in Korea. Here we present the overall study design, endpoints, cohort definition, analysis methods, and procedural details.

\section{Materials and methods}

\section{Study design and principle}

The LG Growth Study (LGS) is a noninterventional registry study to evaluate the long-term safety and effectiveness of four rhGH products - three daily rhGHs (Eutropin inj., Eutropin AQ inj., and Eutropin Pen inj.) and one weekly rhGH (Eutropin Plus inj.) - in real-life clinical setting. The study comprises of the following five cohorts according to the indication under which rhGH is prescribed: GHD, ISS, TS, SGA, and CRF. Children aged at least 2 years or more are eligible for participating in the LGS if they have been treated or are in need of treatment with any of the four rhGH products and satisfy the specific eligibility criteria (refer to cohort profile section). Study objectives and rationale, procedural details, definition of study population, study endpoints and assessment timepoints, statistical analysis methods, and responsibilities of study personnel are prespecified in the written protocol, which is reviewed and approved by the Institutional Review Board (IRB) where their

\section{A. Study scheme for a patient whose rhGH treatment is started at the time of registration}

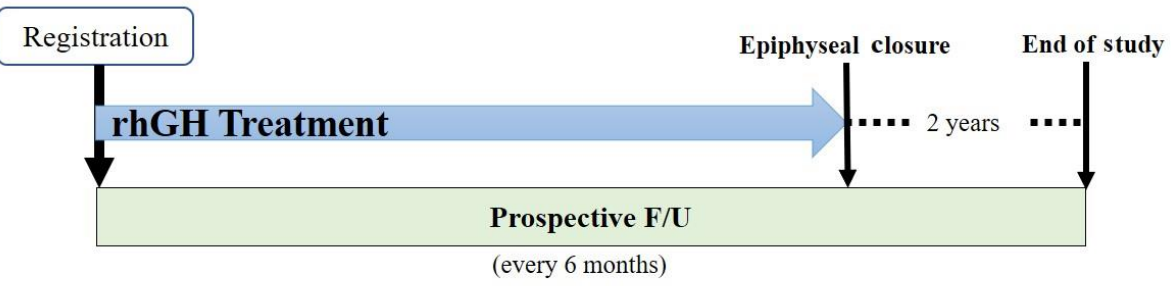

B. Study scheme for a patient whose rhGH treatment is ongoing at the time of registration

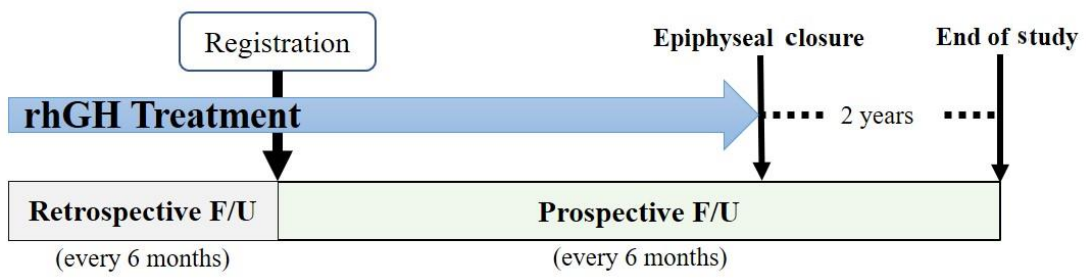

Fig. 1. Study scheme. Study data collection is prospective in nature (A); however, if a patient is registered during the course of recombinant human growth hormone $(\mathrm{rhGH})$ treatment, pretreatment (baseline) information and data obtained thereafter are collected retrospectively (B). For all patients including those who are withdrawn from the treatment before reaching adult height, the follow-up (F/U) continues until 2 years are passed after epiphyseal closure. 
standard operation procedure mandated IRB approval for the observational study. Before any study-related activities, written informed consent is obtained from parents/legal guardians and written informed assent is also obtained from patients who can read and understand Korean. The study is prospective in nature; therefore, all the patients are followed up from the day of registration until reaching 2 years after epiphyseal closure; however, posttreatment data are retrospectively collected as well if a patient is registered in the midst of treatment (Fig. 1). The study is to be conducted in accordance with the regulatory requirements of Ministry of Food and Drug Administration, Korea and standard operating procedures of the Sponsor. The study was registered at ClinicalTrials.gov (identifier: NCT01604395).

\section{Assessment of study endpoints}

After screening procedure, eligible patients are followedup every 6 months until 2 years after epiphyseal closure. Following data are collected: parents' heights, sex, birth date, medical history, pretreatment GH stimulation test result, height, body weight, bone age (BA), sexual maturity using Tanner stage, laboratory test results, concomitant medications, and adverse events (Table 1). No tests or procedures are done for the investigational purposes. For patients who already had started treatment with rhGH at the time of screening, pre- and posttreatment data available before screening are collected retrospectively at 6-month interval. All the study related data are captured on the electronic case report form. To assess the safety of rhGH products, any reported adverse events are collected along with the abnormal laboratory results. For effectiveness evaluation, height, height velocity (HV), height standard deviation score (SDS) for chronological age (CA), and pharmacodynamic markers such as IGF-I and IGF-binding protein 3 (IGFBP-3) will be analyzed. HV is calculated using following formula: $\mathrm{HV}(\mathrm{cm} / \mathrm{yr})=$ height change from baseline/ (date of measurement - date of baseline height measurement $+1) \times 365$. For computation of height SDS for CA, following equation is used referencing the Box-Cox transformation (L), median (M), and coefficient of variation (S) values from growth standard for Korean children and adolescents ${ }^{17)}$ : height $\mathrm{SDS}=[$ Power $($ measured height $/ \mathrm{M}, \mathrm{L})-1] / \mathrm{L} \times \mathrm{S}$. Meanwhile, SDS for IGF-I and IGFBP-3 will be computed using following equation: $\mathrm{SDS}=($ measured value - mean population value $) / \mathrm{SD}$ of population value. ${ }^{18)}$

\section{Statistical analysis}

As the primary purpose of the study is to evaluate the longterm safety of rhGH, the sample size was estimated to detect a rare adverse event such as cancer. Based on a total number of 3,000 patients, the probability of observing at least one cancer is $95 \%$, assuming an overall incidence of $0.1 \%$. ${ }^{19)}$ Hence, the enrollment target was calculated as 4,000 patients considering $25 \%$ of drop-out rate. Principally, all the observed cases will be included in the analysis and missing data will not be imputed. Registered patients receiving at least one dose of rhGH are to be included in the safety analysis if any available data are collected. Adverse events will be coded using MedDRA (version 16.0); events whose causal relationship with the drug could not be assessable or ruled out will be classified as adverse drug reactions; and the incidence rate will be reported with the unit of person-years. For effectiveness analysis, patients with important protocol deviations, such as lack of baseline or

Table 1. Study procedures and time points of key information collection over the course of LG Growth Study

\begin{tabular}{|c|c|c|c|}
\hline Study procedures and time points & Baseline & On-treatment follow-up (every 6 months) & Off-treatment follow-up (every 6 months) \\
\hline Informed consent & $\times$ & - & - \\
\hline Eligibility check & $\times$ & - & - \\
\hline Enrollment & $\times$ & - & - \\
\hline Baseline information $^{\dagger}$ & $x$ & - & - \\
\hline GH stimulation test & $\times$ & - & - \\
\hline Auxological measurement $^{\ddagger}$ & $\times$ & $\times$ & $x$ \\
\hline Bone age & $\times$ & $\times$ & - \\
\hline Sexual maturity ${ }^{5}$ & $\times$ & $x$ & - \\
\hline Laboratory tests" & $\times$ & $\times$ & - \\
\hline rhGH treatment" & $\times$ & $x$ & - \\
\hline Concomitant medications & $\times$ & $\times$ & $\times$ \\
\hline Adverse events $^{* *}$ & - & $x$ & $x$ \\
\hline Study completion & - & $\times$ & $\times$ \\
\hline \multicolumn{4}{|c|}{$\begin{array}{l}\text { "Follow-up is continued for } 2 \text { more years after epiphyseal closure. }{ }^{\dagger} \text { Sex, birth date, parents' heights, medical history, and diagnosis } \\
\text { are collected as baseline information. "The measurement interval is } 6 \text { months: a standing height is measured with the Harpenden } \\
\text { stadiometer and a body weight is measured on a digital scale. }{ }^{\S} \text { Sexual maturity is assessed according to Tanner stage. "Laboratory tests } \\
\text { include insulin-like growth factor (IGF) I, IGF-binding protein 3,T4, free T4, thyroid-stimulating hormone, and glycated hemoglobin, which } \\
\text { are part of routine clinical check-up. "Name of the prescribed product and dates of treatment start and cessation are collected. "Adverse } \\
\text { event, start and end date, seriousness, intensity, frequency, relationship with recombinant human growth hormone (rhGH), action taken } \\
\text { with the dose, and outcome are collected. }\end{array}$} \\
\hline
\end{tabular}




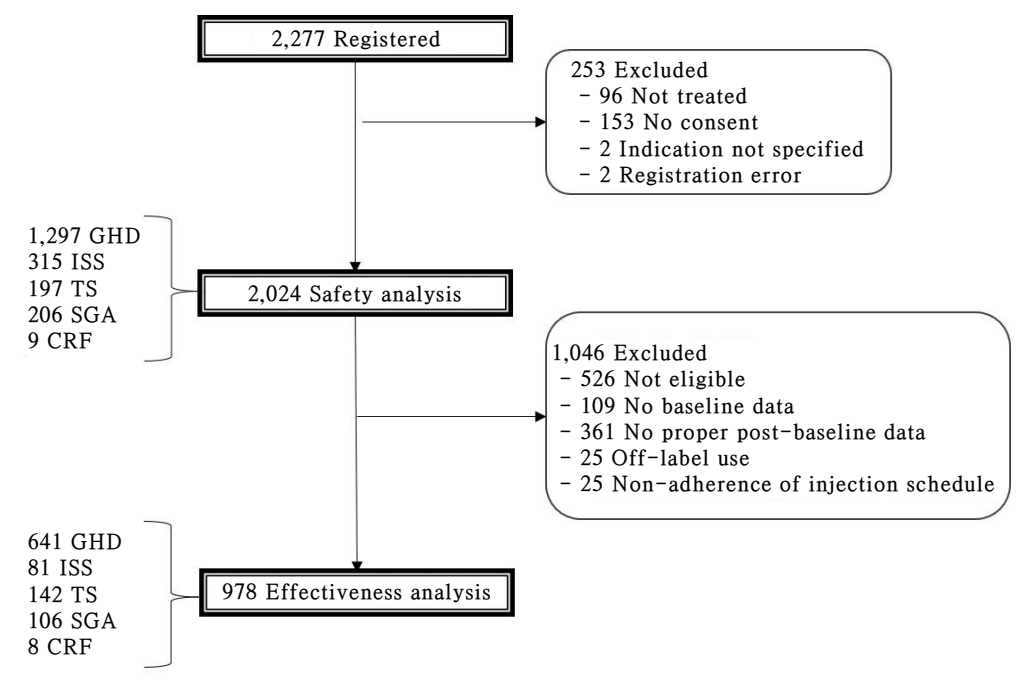

Fig. 2. Patient distribution. Since the initiation of the study on 9 November 2011 , around $50 \%$ of the targeted number of patients' data have been pooled into the database as of 22 March 2017.

Table 2. Number of registered patients from 2012 to 2016

\begin{tabular}{lcc}
\hline Year & No. of registered patients/yr & Accumulated No. of patients \\
\hline 2012 & 717 & 717 \\
2013 & 579 & 1,296 \\
2014 & 247 & 1,543 \\
2015 & 343 & 1,886 \\
2016 & 310 & 2,196
\end{tabular}

The numbers in the left column are the number of registered patients in each year whereas those in the right column are the cumulative number of patients at the end of each year. Since the initiation of LG Growth Study (LGS) registry on 9 November 2011, patients in need of recombinant human growth hormone have been continually registered in the LGS registry.

posttreatment height measurement, receiving rhGH for an offlabel use, or violating major eligibility criteria, will be excluded. Effectiveness end points and laboratory items will be presented with descriptive statistics and the differences from screening will be tested using paired $t$-test. Results with the $P$-value less than 0.05 will be considered statistically significant. All statistical analyses will be performed using SAS software ver. 9.4 (SAS Institute, Cary, NC, USA).

\section{Accumulated data size and data share plan}

Annual interim analysis is to be carried out and the results are to be reviewed by the Observational Study Monitoring Board (OSMB) on behalf of the investigators. Part of interim analyses results were previously shared at three scientific meetings $^{20-22)}$ and the pooled interim data can be published in a peer review journal at the decision of OSMB. After the last patient's last follow-up, the final analysis will be carried out and the results will be reported in a relevant journal. Since the LGS registry was initiated on 9 November 2011, total of 73 sites have participated in the study. More than a quarter of the target number of patients were recruited within the first 2 years and the registration activities have been actively ongoing (Table 2). As of 22 March 2017, the numbers of patients whose data are included in the safety set and effectiveness analysis set are 2,024 and 978, respectively (Fig. 2).

\section{Results}

GHD (64.1\%) was the most commonly treated condition followed by ISS (15.6\%), SGA (10.2\%), TS (9.7\%), and CRF $(0.4 \%)$. At the time of registration, $52 \%(1,048)$ were boys; more than $70 \%(1,439)$ were aged between 6 and 15 years (interquartile range $[\mathrm{IQR}], 5,11$ ); and majority were at Tanner stage I ( $82.9 \%$ based on breast/external genitalia, $96.5 \%$ on pubic hair). Median height SDS was -2.26 (IQR, -2.69 to -2.0) and median BA delay (years) was - 1.46 (IQR, -2.26 to -0.78) (Table 3). As weekly rhGH is currently indicated only for GHD, majority of the registered patients $(80.3 \%)$ were prescribed with daily rhGH.

\section{GH deficiency cohort}

Patients with GHD should meet the following conditions: height $\leq 3$ rd percentile for age and sex, delayed BA, and confirmed GHD with at least $2 \mathrm{GH}$ stimulation tests (peak responses from both tests $<10 \mathrm{ng} / \mathrm{mL}$ ) - but for complete idiopathic GHD, they should be $<5 \mathrm{ng} / \mathrm{mL}$ and the other cases are classified as partial idiopathic GHD or confirmed organic causes of GHD, such as damage to the hypothalamic-pituitary region by radiation, brain damage, anticancer treatment, inflammation, and/or deformation. For GHD, the approved dose of daily rhGH is $0.17-0.21 \mathrm{mg} / \mathrm{kg} / \mathrm{wk}$ (or $4 \mathrm{mg} / \mathrm{m}^{2}$ ), which is divided into equal daily doses and given 6 times per week. The weekly rhGH is approved only for GHD and its recommended 
Table 3. Demographic characteristics at registration (safety set)

\begin{tabular}{|c|c|c|c|c|c|c|}
\hline Variable & Total & GHD & TS & CRF & SGA & ISS \\
\hline No. of patients & $2,024(100)$ & $1,297(64.1)$ & $197(9.7)$ & $9(0.4)$ & $206(10.2)$ & $315(15.6)$ \\
\hline Male & $1,048(51.8)$ & $771(59.4)$ & $0(0)$ & $6(66.7)$ & $104(50.5)$ & $167(53.0)$ \\
\hline Female & $976(48.2)$ & $526(40.6)$ & $197(100)$ & $3(33.3)$ & $102(49.5)$ & $148(47.0)$ \\
\hline Age (yr) & $n=2,024$ & $n=1,297$ & $n=197$ & $n=9$ & $n=206$ & $n=315$ \\
\hline Median (range) & $8(2-19)$ & $8(2-19)$ & $9(2-18)$ & $8(2-15)$ & $6(2-14)$ & $9(2-16)$ \\
\hline $\mathrm{IQR}$ & $(5-11)$ & $(5-11)$ & $(5-11)$ & $(2-13)$ & $(5-9)$ & $(6-11)$ \\
\hline \multicolumn{7}{|c|}{ Age distribution (yr) } \\
\hline $0-5$ & $573(28.3)$ & $370(28.5)$ & $51(25.9)$ & $3(33.3)$ & $80(38.8)$ & $69(21.9)$ \\
\hline $6-10$ & $938(46.3)$ & $591(45.6)$ & 87 (44.2) & $3(33.3)$ & $105(51.0)$ & $152(48.3)$ \\
\hline $11-15$ & $501(24.8)$ & $330(25.4)$ & $54(27.4)$ & $3(33.3)$ & $21(10.2)$ & $93(29.5)$ \\
\hline$>15$ & $12(0.6)$ & $6(0.5)$ & $5(2.5)$ & $0(0.0)$ & $0(0.0)$ & $1(0.3)$ \\
\hline Height SDS & $n=1,471$ & $n=922$ & $n=157$ & $n=8$ & $n=152$ & $n=232$ \\
\hline Median (range) & $-2.26(-6.97$ to 6.23$)$ & $-2.25(-6.97$ to 6.23$)$ & $-2.58(-6.34$ to -0.66$)$ & $-2.43(-3.54$ to 0$)$ & $-2.23(-5.14$ to -0.18$)$ & $-2.17(-5.31$ to 1.54$)$ \\
\hline $\mathrm{IQR}$ & $(-2.69$ to -2.0$)$ & $(-2.64$ to -2.01$)$ & $(-3.31$ to -2.14$)$ & $(-3.26$ to -1.72$)$ & $(-2.64$ to -2.02$)$ & $(-2.61$ to -1.85$)$ \\
\hline Weight SDS & $n=1,484$ & $n=934$ & $n=160$ & $n=8$ & $n=151$ & $n=231$ \\
\hline Median (range) & $-1.64(-9.59$ to 2.78$)$ & $-1.59(-9.59$ to 2.78$)$ & $-1.18(-5.93$ to 2.27$)$ & $-1.55(-4.43$ to -0.12$)$ & $-2.11(-6.47$ to 0.85$)$ & $-1.76(-7.33$ to 1.26$)$ \\
\hline $\mathrm{IQR}$ & $(-2.36$ to -0.91$)$ & $(-2.32$ to -0.91$)$ & $(-2.09$ to -0.33$)$ & $(-3.13$ to -0.83$)$ & $(-2.78$ to -1.57$)$ & $(-2.4$ to -1.02$)$ \\
\hline BMI SDS & $n=1,453$ & $n=915$ & $n=156$ & $n=8$ & $n=149$ & $n=225$ \\
\hline Median (range) & $-0.27(-16.88$ to 3.47$)$ & $-0.23(-16.88$ to 2.88$)$ & 0.51 (-1.92 to 3.47) & $-0.89(-2.89$ to 1.61$)$ & $-0.81(-5.6$ to 2.09$)$ & -0.58 (-4.6 to 2.69$)$ \\
\hline $\mathrm{IQR}$ & $(-1.04$ to 0.52$)$ & (-0.98 to 0.53$)$ & $(-0.39$ to 1.25$)$ & $(-1.72$ to 0.51$)$ & $(-1.35$ to -0.1$)$ & $(-1.29$ to 0.14$)$ \\
\hline IGF-I SDS & $n=1,601$ & $n=1,035$ & $n=146$ & $n=4$ & $n=158$ & $n=258$ \\
\hline Median (range) & $-0.82(-3.6$ to 8.86$)$ & $-0.91(-3.6$ to 7.36$)$ & $-0.59(-2.17$ to 8.86$)$ & $-0.58(-0.79$ to -0.26$)$ & $-0.57(-2.43$ to 3.82$)$ & -0.7 (-2.93 to 3.28$)$ \\
\hline $\mathrm{IQR}$ & $(-1.29$ to -0.32$)$ & $(-1.37$ to -0.43$)$ & $(-1.12$ to 0.1$)$ & $(-0.73$ to -0.37$)$ & $(-1.08$ to 0.04$)$ & $(-1.2$ to -0.26$)$ \\
\hline $\mathrm{BA}(\mathrm{yr})$ & $n=1,663$ & $n=1,072$ & $n=157$ & $n=7$ & $n=166$ & $n=261$ \\
\hline Median (range) & $6.8(0.6-17)$ & $6(0.6-17)$ & $8.5(1-14)$ & $8.8(1.5-13.5)$ & $5.5(1.5-13.5)$ & $8.4(2-15.6)$ \\
\hline IQR & $(4-9.5)$ & $(3.5-9)$ & $(5-10.8)$ & $(2-12.6)$ & $(4-8.5)$ & $(5-11)$ \\
\hline BA-CA (yr) & $n=1,662$ & $n=1,071$ & $n=157$ & $n=7$ & $n=166$ & $n=261$ \\
\hline Median (range) & $-1.46(-8.83$ to 4.49$)$ & $-1.71(-8.83$ to 2.71$)$ & $-0.87(-5.75$ to 2.53$)$ & $-1.69(-4.87$ to 0.3$)$ & $-1.05(-4.67$ to 2.51$)$ & $-0.98(-5.3$ to 4.49$)$ \\
\hline IQR & $(-2.26$ to -0.78$)$ & $(-2.48$ to -1.03$)$ & $(-1.68$ to -0.16$)$ & $(-4.22$ to -0.62$)$ & $(-1.67$ to -0.36$)$ & $(-1.87$ to -0.26$)$ \\
\hline
\end{tabular}

Values are presented as number (\%) unless otherwise indicated.

Percentages may not add up to 100\%, as they are rounded to the nearest percent. Range is presented from minimum to maximum. GHD, growth hormone deficiency; TS, Turner Syndrome; CRF, chronic renal failure; SGA, small for gestational age; ISS, idiopathic short stature; SDS, standard deviation score; BMI, body mass index; IGF-I, insulin-like growth factor I; BA, bone age; CA, chronological age; IQR, interquartile range.

dose is $0.5 \mathrm{mg} / \mathrm{kg}$, given once weekly.

So far, more than $90 \%$ of the registered GHD patients were classified as idiopathic GHD (complete idiopathic GHD, 315; partial idiopathic GHD, 848) and 107 patients were confirmed to have organic lesions responsible for GHD. It is noted that more boys than girls (59.4\% vs. 40.6\%) are treated for GHD and BA delay in this cohort (median BA delay, -1.71 years) is more severe than the other cohorts except CRF cohort. Median treatment duration (years) for GHD cohort is 3.38 (IQR, 1.96$4.82)$.

\section{ISS cohort}

For patients with ISS, stunted growth (height $\leq 3$ rd percentile for age and sex) and normal GH secretion confirmed by GH concentration $\geq 10 \mathrm{ng} / \mathrm{mL}$ to at least one stimulation test should be confirmed. The approved dose for ISS is $0.37 \mathrm{mg} / \mathrm{kg} / \mathrm{wk}$, which is divided into 6 doses and given 6 times per week.
Although ISS is quite a commonly encountering condition, ISS cohort composes only $15.6 \%$ of the whole population, which reflects prudent approach in prescribing rhGH for this condition. Median treatment duration (years) for ISS cohort is 2.07 (IQR, 1.07-3.55).

\section{Turner syndrome cohort}

Patients with TS should be confirmed to have chromosome abnormality as well as characteristic phenotypes. The approved dose for TS is $0.33 \mathrm{mg} / \mathrm{kg} / \mathrm{wk}$, which is divided into daily doses and given 6-7 times per week.

This cohort represents children with the most severely stunted growth: median height SDS, -2.58 (IQR, -3.31 to -2.14). Median treatment duration (years) for TS cohort is 4.87 (IQR, $3.23-7.23)$, which is longer than the other cohorts. 


\section{SGA cohort}

For patients with SGA, stunted growth (height $\leq 3$ rd percentile for age and sex) along with low birth weight ${ }^{23)}$ or height $(<10$ th percentile or $<-2$ SD for gestational age) should be confirmed. The approved dose for SGA is $0.48 \mathrm{mg} / \mathrm{kg} / \mathrm{wk}$, which is divided into daily doses and given 6-7 times per week.

This cohort is mostly composed by patients under 11 years (89.8\%) and underweighted patients (median body mass index of 15.14 [IQR, 14.24-15.94]). The median treatment duration (years) for SGA is 1.77 (IQR, 1.16-2.44).

\section{CRF cohort}

For patients with CRF, stunted growth (annual $\mathrm{HV}<4 \mathrm{~cm} /$ yr or height $\leq 3$ rd percentile for age and sex) and delayed BA compared with CA should be confirmed. The approved dose for CRF is $0.05 \mathrm{mg} / \mathrm{kg} / \mathrm{day}$, which is given daily.

Still only 9 patients' data are available for this cohort but we expect more data to come. The median treatment duration (years) for CRF is 4.09 (IQR, 1.6-4.92).

\section{Discussion}

As a tool to assess the safety and efficacy of a medical intervention, properly designed and executed randomized controlled trials (RCTs) are identified as studies with goldstandard design generating the highest quality of evidence. ${ }^{24,25)}$ Most of the efficacy confirmatory trials conducted for the purpose of regulatory approval are designed as RCTs. Nevertheless, not always RCTs can serve as an ideal platform to attain the data. For some type of research questions, such as disease prognosis will be solved out better by the largescale prospective cohort studies rather than by RCTs. Besides, as we all recognize several essential features of RCTs to strengthen internal validity, such as highly-selected population or standardized treatment regimen, sometimes jeopardize the applicability of the data. Hence, the body of evidence should be balanced with the data collected from studies reflecting reallife practices such as pragmatic trials, long-term prospective cohort studies, registry studies, etc. In case of rhGH treatment, its impact on adult height and long-term safety profile, which can be often exempted in regulatory trials (phases 1-3) of noninferiority design to prove short-term efficacy, have been more frequently evaluated in large observational studies or registry studies. Considering the prolonged treatment period of rhGH, usually at least 5 years up to life-long treatment, the history of rhGH usage is still short, which necessitates the ongoing monitoring of the effectiveness and safety of rhGH treatment in various populations. Moreover, several topics still require our attention such as malignancies or cardiovascular risk associated with rhGH use during childhood or nonstandardized dosing regimen as shown in recent analysis from a large registry dataset. ${ }^{26)}$ To meet such needs and to expand the limit of knowledge, several large observational or registry studies have been conducted in Europe and America and many interim analyses have been published in diverse topics. ${ }^{27-32)}$ In line with these recent research efforts, the LGS was initiated to fulfill several purposes. Foremost, it is the first long-term prospective and also retrospective for treatment-ongoing patients at the time of registration cohort study in Korean pediatric patients with well-defined endpoints. Although this study is not powered to detect very rare adverse events $(<1: 10,000)$, it will capture the whole spectrum of safety profile of rhGH from initiation of treatment until adolescence with the primary objective of detecting malignancies. Available data do not indicate the increased risk of new primary cancers or recurrence of previous primary cancers in pediatric patients receiving rhGH, still the evidences are not enough to make a definitive conclusion. ${ }^{6}$ This study will be the first study to evaluate the cancer risk of rhGH in Korean children. Besides, the current sample size is enough to evaluate the risk of type 2 diabetes mellitus, which is known as a common adverse event related with rhGH based on the global registry data but was relatively less defined in the small-scale postmarketing surveillance study $(n=438)$ of Eutropin inj. Along with the important safety data, the study will also provide overall disease distribution data, demographic characteristics of each condition, treatment compliance pattern, and comparative effectiveness and safety between different disease entities. Moreover, it will enable us to compare the safety profile of weekly rhGH with that of daily rhGH. One potential drawback of daily rhGH stems from the fact that they need to be injected on a daily basis, and according to literature, poor compliance to this regimen is frequent among patients on rhGH therapy which may negatively affect the treatment outcome. ${ }^{33-36}$ Therefore, if the weekly formulation does not present no added safety risk even after long-term follow-up while it shows similar effectiveness, it can be the alternative treatment option for daily rhGH in longer perspective.

Meanwhile, the LGS have the following potential limitations. Firstly, this registry study does not provide the level of evidence that randomized controlled study does and the data will be based on heterogenous groups of patients diagnosed under different practices. Secondly, potential selection bias may exist because of selection of investigational sites. Even though most of the major hospitals prescribing rhGH are included to the study, not all hospitals in Korea are covered. Thirdly, the laboratory tests were performed at each site not by a central laboratory; therefore, the interpretation of the descriptive data should be accompanied with the review of individual results and analysis method. Lastly, we did not plan to investigate the quality of life and psychological impact on patients.

To conclude, the standardized and complete dataset generated from this multicenter registry study will allow us to evaluate rare adverse events and long-term effectiveness of rhGH usually unavailable from clinical studies conducted for a regulatory approval. Based on about 4,000 Korean pediatric patients' data, effectiveness and safety profile of rhGH prescribed to various conditions will be evaluated and the evidences obtained from 
this study are expected to provide practical insights on the reallife practices.

\section{Conflict of interest}

No potential conflict of interest relevant to this article was reported.

\section{Acknowledgments}

This cohort study was supported by LG Chem, Ltd. The authors would like to thank all the principal investigators of "LG Growth Study." The principle investigators of LGS (in alphabetical order) are available at https://doi.org/10.6065/ apem.2018.23.1.43.

\section{References}

1. Romero CJ, Dauber AN, Cohen LE. Childhood growth hormone deficiency and hypopituitarism. In: Radovick S, MacGillivray MH, editors. Pediatric endocrinology: a practical clinical guide. 2nd ed. New York: Humana Press, 2013:3-28.

2. Brown P, Brandel JP, Sato T, Nakamura Y, MacKenzie J, Will RG, et al. Iatrogenic Creutzfeldt-Jakob disease, final assessment. Emerg Infect Dis 2012;18:901-7.

3. Navarro R, Dunn JD, Lee PA, Owens GM, Rapaport R. Translating clinical guidelines into practice: the effective and appropriate use of human growth hormone. Am J Manag Care 2013;19(15 Suppl):s281-9.

4. Franklin SL, Geffner ME. Growth hormone: the expansion of available products and indications. Pediatr Clin North Am 2011;58:1141-65, x.

5. Kemp SF, Frindik JP. Emerging options in growth hormone therapy: an update. Drug Des Devel Ther 2011;5:411-9.

6. Allen DB, Backeljauw P, Bidlingmaier M, Biller BM, Boguszewski M, Burman P, et al. GH safety workshop position paper: a critical appraisal of recombinant human GH therapy in children and adults. Eur J Endocrinol 2016;174:P1-9.

7. Romer T, Saenger P, Peter F, Walczak M, Le Bouc Y, KhanBoluki J, et al. Seven years of safety and efficacy of the recombinant human growth hormone Omnitrope in the treatment of growth hormone deficient children: results of a phase III study. Horm Res 2009;72:359-69.

8. Deodati A, Cianfarani S. Impact of growth hormone therapy on adult height of children with idiopathic short stature: systematic review. BMJ 2011;342:c7157.

9. Stephure DK; Canadian Growth Hormone Advisory Committee. Impact of growth hormone supplementation on adult height in Turner syndrome: results of the Canadian randomized controlled trial. J Clin Endocrinol Metab 2005;90:3360-6.

10. Kim SJ, Kim CW. Development and characterization of sodium hyaluronate microparticle-based sustained release formulation of recombinant human growth hormone prepared by Spray-Drying. J Pharm Sci 2016;105:613-22.

11. Péter F, Bidlingmaier M, Savoy C, Ji HJ, Saenger PH. Three-year efficacy and safety of LB03002, a once-weekly sustained-release growth hormone $(\mathrm{GH})$ preparation, in prepubertal children with GH deficiency (GHD). J Clin Endocrinol Metab 2012;97:400-7.

12. Hwang JS, Lee HS, Chung WY, Han HS, Jin DK, Kim HS, et al. Efficacy and safety of LB03002, a once-weekly sustained-release human $\mathrm{GH}$ for 12-month treatment in Korean children with GH deficiency. Eur J Endocrinol 2013;169:179-85.

13. Khadilkar V, Radjuk KA, Bolshova E, Khadgawat R, El Kholy M, Desai M, et al. 24-month use of once-weekly GH, LB03002, in prepubertal children with GH deficiency. J Clin Endocrinol Metab 2014;99:126-32.

14. Lee KH, Lee BC, Ko CW, Jin DK, Yang SW, Yoo HW, et al. A single-arm, phase III study to assess efficacy and safety after 6-month-treatment of EutropinTM Inj. (recombinant human growth hormone) in prepubertal children with short stature due to small for gestational age. J Korean Soc Pediatr Endocrinol 2011;16:157-64.

15. Kim DH, Lee BC, Yang SY, Chung YY. Clinical effects of eutropin (recombinant human growth hormone) in patients with turner syndrome. J Korean Soc Pediatr Endocrinol 1998;3:172-83.

16. Kim HS, Yang SW, Yoo HW, Suh BK, Ko CW, Chung WY, et al. Efficacy of short-term growth hormone treatment in prepubertal children with idiopathic short stature. Yonsei Med J 2014;55:53-60.

17. Korea Centers for Disease Control and Prevention, Division of Chronic Disease Surveillance, Committee for the Development of Growth Standard for Korean Children and Adolescents; Korean Pediatric Society, Committee for School Health and Public Health Statistics. 2007 Korean children and adolescents growth standard (commentary for the development of 2007 growth chart). Cheongju: Korea Centers for Disease Control and Prevention, Division of Chronic Disease Surveillance, 2007.

18. Hyun SE, Lee BC, Suh BK, Chung SC, Ko CW, Kim HS, et al. Reference values for serum levels of insulin-like growth factor-I and insulin-like growth factor binding protein-3 in Korean children and adolescents. Clin Biochem 2012;45:16-21.

19. Bell J, Parker KL, Swinford RD, Hoffman AR, Maneatis T, Lippe B. Long-term safety of recombinant human growth hormone in children. J Clin Endocrinol Metab 2010;95:167-77.

20. Kim JH, Hwang IT, Chung S, Rhie YJ, Chae HW, Choong HS. Long-term safety and effectiveness of daily and weekly GH treatment in pediatric patients. In: 54th Annual Conference of the European Society for Paediatric Endocrinology; 2015 Oct 1-3; Barecelona, Spain. Barcelona: The European Society for Paediatric Endocrinology, 
2015;LBP-1270.

21. Chung S, Hwang IT, Rhie YJ, Kim JH, Chae HW, Choi $\mathrm{JH}$, et al. Long-term safety and effectiveness of daily and weekly growth hormone treatment in pediatric GHD patients (4-years' results). In: 55th Annual Conference of the European Society for Paediatric Endocrinology; 2016 Sep 10-12; Paris, France. Paris: The European Society for Paediatric Endocrinology, 2016;RFC15.7.

22. Chung S, Hwang IT, Rhie YJ, Kim JH, Chae HW, Choi $\mathrm{JH}$, et al. Long-term safety and effectiveness of growth hormone treatment in pediatric patients with growth hormone deficiency: interim results of LG growth study. In: 55th Annual conference of the European Society for Paediatric Endocrinology; 2016 Sep 10-12; Paris, France. Paris: The European Society for Paediatric Endocrinology, 2016;LBP11.

23. Lim JS, Lim SW, Ahn JH, Song BS, Shim KS, Hwang IT. New Korean reference for birth weight by gestational age and sex: data from the Korean Statistical Information Service (2008-2012). Ann Pediatr Endocrinol Metab 2014;19:14653.

24. The periodic health examination. Canadian Task Force on the Periodic Health Examination. Can Med Assoc J 1979;121:1193-254.

25. Schulz KF, Altman DG, Moher D; CONSORT Group. CONSORT 2010 statement: updated guidelines for reporting parallel group randomized trials. Ann Intern Med 2010;152:726-32.

26. Blankenstein O, Snajderova M, Blair J, Pournara E, Pedersen BT, Petit IO. Real-life GH dosing patterns in children with GHD, TS or born SGA: a report from the NordiNet ${ }^{\circ}$ International Outcome Study. Eur J Endocrinol 2017;177:145-55.

27. Höybye C, Sävendahl L, Christesen HT, Lee P, Pedersen BT, Schlumpf M, et al. The NordiNet International Outcome Study and NovoNet ANSWER Program : rationale, design, and methodology of two international pharmacoepidemiological registry-based studies monitoring long-term clinical and safety outcomes of growth hormone therapy (Norditropin ${ }^{\circ}$ ). Clin Epidemiol 2013;5:119-27.
28. Swerdlow AJ, Cooke R, Albertsson-Wikland K, Borgström B, Butler G, Cianfarani S, et al. Description of the SAGhE Cohort: A Large European Study of Mortality and Cancer Incidence Risks after Childhood Treatment with Recombinant Growth Hormone. Horm Res Paediatr 2015;84:172-83.

29. Pfäffle R, Schwab KO, Marginean O, Walczak M, Szalecki M, Schuck E, et al. Design of, and first data from, PATRO Children, a multicentre, noninterventional study of the long-term efficacy and safety of Omnitrope $\left(^{\circ}\right)$ in children requiring growth hormone treatment. Ther Adv Endocrinol Metab 2013;4:3-11.

30. ClinicalTrials.gov. Observational Study of Somatropin Treatment in Children (GeNeSIS) [Internet]. Bethesda (MD): U.S. National Library of Medicine; [cited 2017 May 31]. Available from: https://www.clinicaltrials.gov/ct2/ show/NCT01088412.

31. Pfizer Inc. KIGS-How It All Started. [Internet]. Sollentuna (Sweden): Pfizer Health AB Vetenskapsvägen; 2008 2016 [cited 2017 May 31]. Available from: https:// medicaloutcomes.pfizer.com/kigs/publications/kigs-howit-all-started.

32. ClinicalTrials.gov. National Cooperative Growth Study (NCGS) of optimal nutropin AQ and nutropin dosing in pubertal growth hormone-deficient (GHD) patients [Internet]. Bethesda (MD): U.S. National Library of Medicine; [cited 2017 May 31]. Available from: https:// clinicaltrials.gov/ct2/show/NCT00097513.

33. Lanes R. Long-term outcome of growth hormone therapy in children and adolescents. Treat Endocrinol 2004;3:53-66.

34. Desrosiers P, O'Brien F, Blethen S. Patient outcomes in the GHMonitor: the effect of delivery device on compliance and growth. Pediatr Endocrinol Rev 2005;2 Suppl 3:327-31.

35. Kapoor RR, Burke SA, Sparrow SE, Hughes IA, Dunger $\mathrm{DB}$, Ong KK, et al. Monitoring of concordance in growth hormone therapy. Arch Dis Child 2008;93:147-8.

36. Cutfield WS, Derraik JG, Gunn AJ, Reid K, Delany T, Robinson E, et al. Non-compliance with growth hormone treatment in children is common and impairs linear growth. PLoS One 2011;6:e16223. 